\title{
Analysis of the effect on propagation of voltage sag considering different winding connection modes of transformer
}

\author{
Jiming Chen ${ }^{\text {a }}$, Lizhi Qi, Guiyue Jin and Yongduan Xue \\ College of Information and Control Engineering, China University of Petroleum (East China), Qingdao 266580, \\ Shandong Province, China
}

\begin{abstract}
The effects of transformers on the types and characteristics of voltage sag are also different when the voltage sag is transmitted by the transformers, which have different winding connection modes. In this paper, using the system simulation model built by PSCAD, based on the derivation of voltage transfer matrix of transformers with different winding connection modes. Then, taking the $\mathrm{Y}_{0} / \mathrm{Y}-12$ type transformer as an example analysed the propagation characteristics of voltage sag caused by single line-to-ground fault, line-to-line fault and double line-to-ground fault. The transfer law of voltage sag propagation of transformers with different winding connection modes is summarized. These laws provide some reference value with on line monitoring, type identification, source location of voltage sag and state evaluation. Industrial plants could reduce the harm caused by the voltage sag reasonable by the way of changing winding connection modes of transformer.
\end{abstract}

Keywords: power quality; voltage sag; voltage sag propagation characteristics; transformer winding connections.

\section{Introduction}

In recent years, power quality problem has become a worldwide extensive discussion and research focus, along with the power electronic equipment and voltage sensitive equipment in a large number of applications in industrial control and production process. Voltage sags have caused wide concern of the power quality issues, including the power supply department and the customers [1]. According to national standard GB/T 30137-2013 power quality-voltage sags and short interruptions voltage sags are defined as: a certain point voltage RMS value suddenly reduced to 0.1-0.9, and recover the normal phenomenon in the short duration 10ms-1min, similar definition of IEEE, while scope of the effective value in IEC is defined between 0.01-0.9 times rated voltage, duration of 0.5 cycle to 3 minutes [2-4].

Voltage sags are mainly caused by symmetrical or asymmetrical fault occurs in the power system. In addition, the starting of large induction motor and switching of transformer can also cause voltage sags [5]. Voltage sags occur very frequently, the economic loss caused by voltage sags accounts for $60 \%$ of the total loss of industrial samples [6]. For examples, the SAIC GM experienced in a total of 31 times voltage sags from 2004 January to 2005 April, an average of 2 times a month; the occurrence of voltage sags are more than 1000 times each year (from 2010 to 2013) in Shenzhen power grid, and

\footnotetext{
a Corresponding author : jimingchen@126.com
} 
even reached more than 3000 times in 2012 [7].

Voltage sags of power grid have serious harms to the industrial production process, although it is not a serious accident of electric power. Even several cycles of voltage sags will affect the normal work of voltage sensitive equipment, causing adjustable speed drives tripping, the disorder of programmable logic controller, malfunction of loss pressure release device, resulting in huge economic losses [8-11]. Statistics show that a temporary sag in voltage on a rolling mill usually results economic losses about $\$ 10000$ on an average [12]. It is said that the complaints of customers caused by voltage sags accounted for more than $80 \%$ [13-14].

\section{Propagation of voltage sags}

\subsection{Propagation of voltage sags through transformers}

A large part of the power users will experience voltage sag when the system transmission line failure. They will still be affected by voltage sag, even if the electrical distance is very far between the bus and the fault location. For the same fault, the characteristics of voltage sag in user terminals can also be different from each other, and characteristics of sag can also be different from the initial fault points. The difference of voltage sags, such as the amplitude and phase, a large part of the reason is that the signal from the initial point of fault location through a transformer spread to the user terminal. So it is very necessary to study the propagation of voltage sags through transformer [15].

The existing literature has pointed out that the voltage amplitude will be greatly improved when voltage sag signal from the low voltage level to the high through the transformer. The voltage amplitude usually greater than 0.8p.u. when take into account the leakage reactance of the transformer. When the high and low voltage side short circuit capacity meets to $S_{K h} \geq 10 S_{K l}$, even if three-phase short circuit occurs in the low-voltage side, the voltage of high will be higher than $0.9 p . u$.. Therefore, the propagation of the voltage sag usually refers to the propagation from the high voltage level to the low voltage level, without taking into account the effect of the low voltage side to the high [16-18].

The reason why voltage sags in the user terminal have different characteristics is because the connection mode of the transformer winding at the bus entrance of the user group. Therefore, the different winding connection of the transformer is the key point of this paper.

\subsection{Transformation matrixes of transformers with different connection}

The characteristics of voltage sags will be changed after voltage is spread by the transformer. Different connection modes of the transformers have different change. The transformers are divided into three types, according to the transmission of zero sequence component in the transformer. The zero sequence equivalent circuits as shown in Fig. 1. Assuming that the ratio of voltage in primary and secondary side is 1: 1 in p.u.. The derivation of Transformation matrixes of transformers with different connection as follows [18]. 


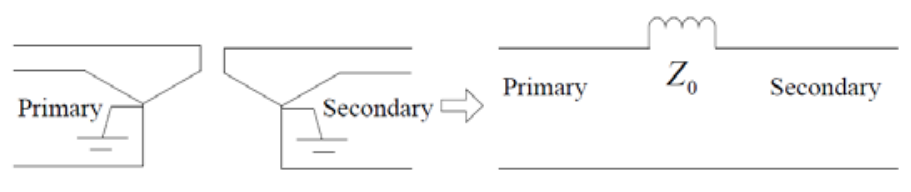

(a) $\mathrm{Y}_{0} / \mathrm{Y}_{0}-12$ Transformer

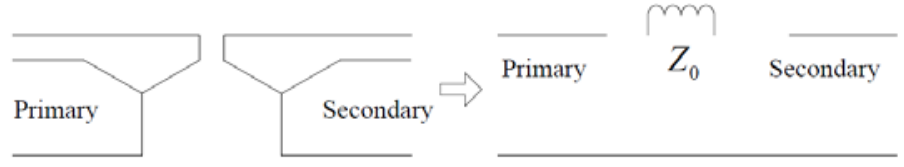

(b) $\mathrm{Y}_{0} / \mathrm{Y}-12$ Transformer

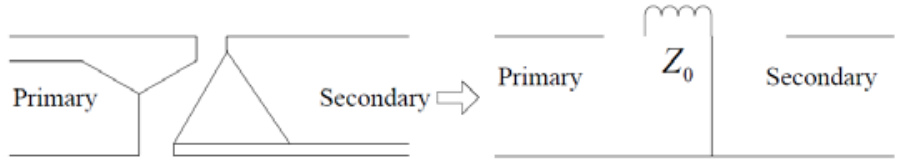

(c) $\mathrm{Y}_{0} / \Delta-11$ Transformer

Figure 1. Zero sequence equivalent circuits of transformer under different winding connection

(1) The winding connection of $Y_{0} / Y_{0}-12$ transformers is star-star connected with both star points grounded and zero sequence equivalent circuit is shown in figure 1- (a). The transformation matrixes of phase voltage and line voltage of this transformer are both unit matrix. Where, $\mathbf{T}_{\mathrm{P}-\mathrm{p}}$ represent the line voltage transformation matrix, and $\mathbf{T}_{\mathrm{P}-\mathrm{N}}$ is the phase voltage transformation matrix, respectively.

$$
\mathbf{T}_{1 \mathrm{P}-\mathrm{P}}=\mathbf{T}_{1 \mathrm{P}-\mathrm{N}}=\mathbf{E}=\left[\begin{array}{lll}
1 & 0 & 0 \\
0 & 1 & 0 \\
0 & 0 & 1
\end{array}\right]
$$

(2) The winding connection of $\mathrm{Y}_{0} / \mathrm{Y}-12\left(\mathrm{Y} / \mathrm{Y}_{0}-12\right.$ or $\left.\mathrm{Y} / \mathrm{Y}-12\right)$ transformers is star-star connected transformer with one or both star points not grounded, and the zero sequence equivalent circuit is shown in figure 1- (b). The voltage equation between PCC (Point of Common Coupling) and positive, negative and zero sequence voltage during the period of the fault is shown as (2).

$$
\left\{\begin{array}{l}
\mathbf{U}_{a}=\mathbf{U}_{1}+\mathbf{U}_{2}+\mathbf{U}_{0} \\
\mathbf{U}_{b}=a^{2} \mathbf{U}_{1}+a \mathbf{U}_{2}+\mathbf{U}_{0} \\
\mathbf{U}_{c}=a \mathbf{U}_{1}+a^{2} \mathbf{U}_{2}+\mathbf{U}_{0}
\end{array}\right.
$$

Where,

$$
\begin{aligned}
& a=e^{j 120^{\circ}}=-\frac{1}{2}+j \frac{\sqrt{3}}{2} \\
& a^{2}=e^{j 240^{\circ}}=-\frac{1}{2}-j \frac{\sqrt{3}}{2}
\end{aligned}
$$

In the form of a matrix is represented as $\mathbf{U}_{A B C}=\mathbf{A} \times \mathbf{U}_{120}$.

Where,

$$
\mathbf{A}=\left[\begin{array}{ccc}
1 & 1 & 1 \\
a^{2} & a & 1 \\
a & a^{2} & 1
\end{array}\right]
$$


Positive, negative and zero sequence voltage during the period of the fault is given by $\mathbf{U}_{120}=\mathbf{A}^{-1} \times \mathbf{U}_{A B C}$.

The sequence diagram shows that the positive, negative and zero sequence components in primary and secondary of the transformer can be given by $\mathbf{U}_{120}^{\prime}=\mathbf{H}_{2} \times \mathbf{U}_{120}$.

Where,

$$
\mathbf{H}_{2}=\left[\begin{array}{lll}
1 & 0 & 0 \\
0 & 1 & 0 \\
0 & 0 & 0
\end{array}\right]
$$

Three-phase voltage value in the secondary of the transformer is:

$$
\mathbf{U}_{a b c}=\mathbf{A} \times \mathbf{U}_{120}^{\prime}=\mathbf{A} \times \mathbf{H}_{2} \times \mathbf{A}^{-1} \times \mathbf{U}_{A B C}
$$

Therefore, phase voltage transformation matrix of $\mathrm{Y}_{0} / \mathrm{Y}-12$ transformer is:

$$
\mathbf{T}_{2 P-N}=\mathbf{A} \times \mathbf{H}_{2} \times \mathbf{A}^{-1}=\frac{1}{3}\left[\begin{array}{ccc}
2 & -1 & -1 \\
-1 & 2 & -1 \\
-1 & -1 & 2
\end{array}\right]
$$

Line voltage transformation matrix of $\mathrm{Y}_{0} / \mathrm{Y}-12$ transformer is unit matrix because there is no zero sequence component in the line voltage.

(3) The winding connection of $\mathrm{Y}_{0} \Delta-11$ or $\mathrm{Y} / \Delta-11$ transformers is star-delta or delta-star transformer, and zero sequence equivalent circuit is shown in figure 1- (c). The positive, negative and zero sequence component in primary and secondary of those transformers is given by $\mathbf{U}_{120}^{\prime}=\mathbf{H}_{3} \times \mathbf{U}_{120}$.

Where,

$$
\mathbf{H}_{3}=\left[\begin{array}{ccc}
e^{j 30^{\circ}} & 0 & 0 \\
0 & e^{-j 30^{\circ}} & 0 \\
0 & 0 & 0
\end{array}\right]
$$

Voltage transformation matrix of those transformers is:

$$
\mathbf{T}_{3 P-N}=\mathbf{T}_{3 P-P}=\frac{1}{\sqrt{3}}\left[\begin{array}{ccc}
1 & -1 & 0 \\
0 & 1 & -1 \\
-1 & 0 & 1
\end{array}\right]
$$

\section{Results and discussion}

In this section, the theoretical analysis is combined with simulation through primary and secondary waveform of $\mathrm{Y}_{0} / \mathrm{Y}-12$ transformer. Propagation characteristics of voltage sags through transformer are analyzed by single phase-to-ground fault, phase-to-phase fault and two phase-to-ground fault. Further analyses of the propagation mechanism of voltage sag are proceed.

Simulation model: in this paper, simulation is carried out by using PSCAD/EMTDC, simplified network model as shown in figure 2. The line models choose PI parameters. The parameters of transformer are SZ9-M-12500/35kV/6.3kV, rated capacity $\mathrm{S}_{\mathrm{N}}=12500 \mathrm{kVA}$, no-load loss $\mathrm{P}_{0}=13680 \mathrm{~W}$ and short-circuit impedance is $8 \%$, no-load current $\mathrm{I}_{0} \%=0.8 \%$, respectively.

Simulation conditions: Setting single phase-to-ground fault (A), phase-to-phase fault $(B, C)$ and two phase-to-ground fault $(\mathrm{B}, \mathrm{C})$, respectively. The start time of the fault at $1 \mathrm{~s}$ and the duration is $0.05 \mathrm{~s}$. Measuring the changes of instantaneous and RMS values of voltage in primary and secondary of transformer during the fault period. 


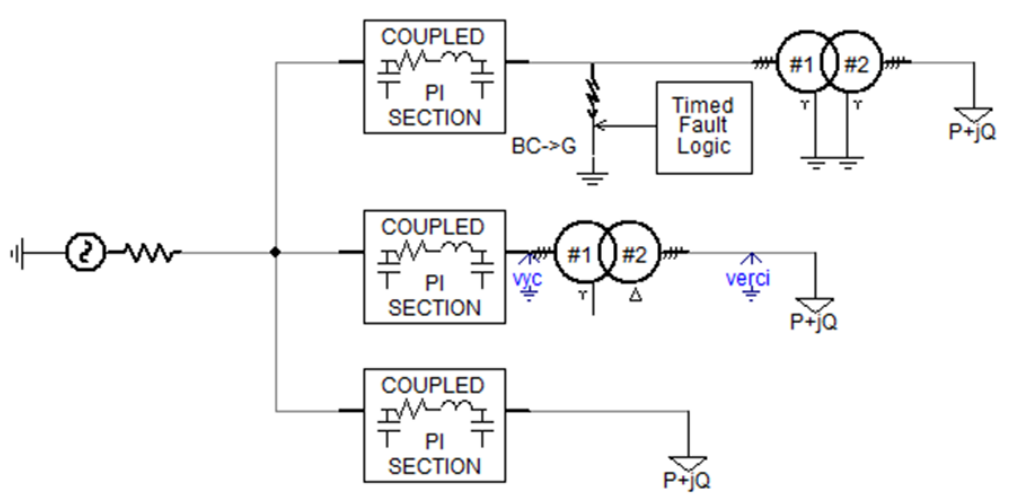

Figure 2. Simplified model of system

\subsection{Single phase-to-ground fault}

Most of the faults in power system are single phase-to-ground fault, and resulting unbalanced voltage sags. Figure 3 shows compound sequence network including the positive, negative and zero sequence component. In the same way, two phase-to-ground fault is also includes the three sequence components.

From the Compound sequence network of single phase-to-ground fault as shown in figure 3, the voltage expressions can be given in (9) when single phase-to-ground fault occurs.

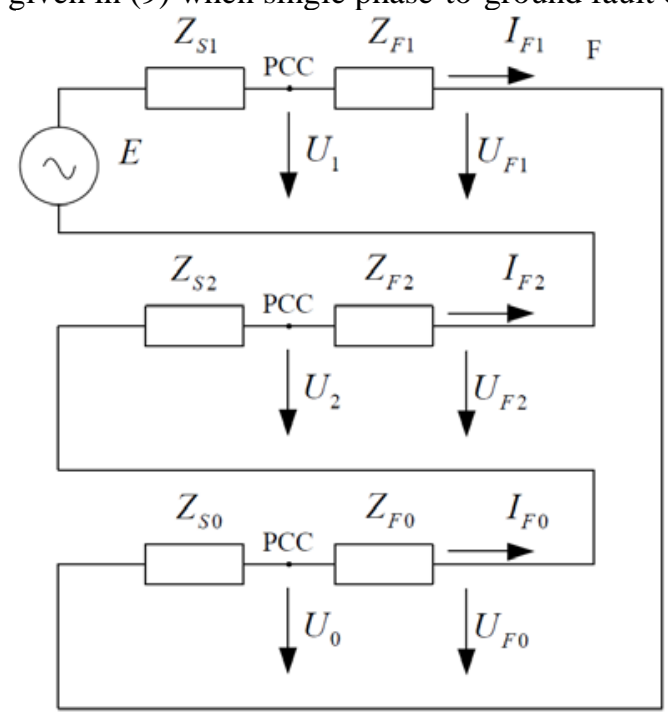

Figure 3. Compound sequence network of single phase-to-ground fault

$$
\mathbf{B}_{1}=\left[\begin{array}{l}
\mathbf{U}_{a} \\
\mathbf{U}_{b} \\
\mathbf{U}_{c}
\end{array}\right]=\left[\begin{array}{c}
V_{1} \\
-\frac{1}{2}-j \frac{\sqrt{3}}{2} \\
-\frac{1}{2}+j \frac{\sqrt{3}}{2}
\end{array}\right]
$$

Where, 
$V_{1}=\frac{Z_{F 1}+Z_{F 2}+Z_{F 0}}{Z_{S 1}+Z_{S 2}+Z_{S 0}+Z_{F 1}+Z_{F 2}+Z_{F 0}}, Z_{S 1}, Z_{S 2}, Z_{S 0}$ represent positive, negative and zero sequence impedances of the system, respectively. $Z_{F 1}, Z_{F 2}, Z_{F 0}$ represent positive, negative and zero sequence impedances between the PCC and the fault location, respectively.

Phase voltage expression in the secondary of the transformer is shown as (10) when the single phase-to-ground fault propagated by $\mathrm{Y}_{0} / \mathrm{Y}-12$ transformer. Voltage waveforms (RMS) in primary and secondary of the transformer are shown in figure 4 when single phase-to-ground fault occurs.

$$
\begin{aligned}
\mathbf{B}_{1}^{\prime \prime} & =\mathbf{T}_{2 P-N} \times \mathbf{B}_{1} \\
& =\frac{1}{3}\left[\begin{array}{ccc}
2 & -1 & -1 \\
-1 & 2 & -1 \\
-1 & -1 & 2
\end{array}\right] \times\left[\begin{array}{c}
V_{1} \\
-\frac{1}{2}-j \frac{\sqrt{3}}{2} \\
-\frac{1}{2}+j \frac{\sqrt{3}}{2}
\end{array}\right]=\left[\begin{array}{c}
\frac{2}{3} V_{1}+\frac{1}{3} \\
-\frac{1}{3} V_{1}-\frac{1}{6}-j \frac{\sqrt{3}}{2} \\
-\frac{1}{3} V_{1}-\frac{1}{6}+j \frac{\sqrt{3}}{2}
\end{array}\right]
\end{aligned}
$$

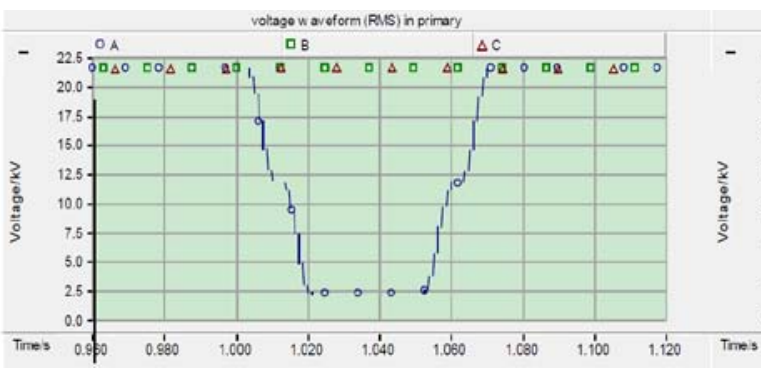

(a)voltage waveform in primary

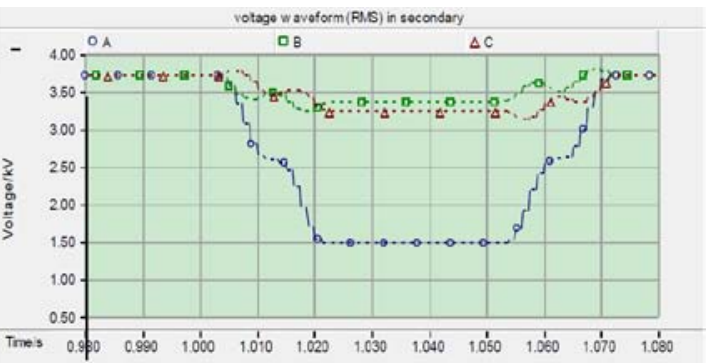

(b)voltage waveform in secondary

Figure 4. Voltage waveforms (RMS) of single phase-to-ground fault with $\mathrm{Y}_{0} / \mathrm{Y}-12$ type transformer

Expression (10) indicates that the amplitude of phase A changed from $V_{1}$ to $\frac{2}{3} V_{1}+\frac{1}{3}$ p.u., the amplitude of phase B and C changed from 1p.u. to $\sqrt{\left(\frac{1}{3} V_{1}+\frac{1}{6}\right)^{2}+\frac{3}{4}}$ p.u. , after voltage sag caused by the single phase-to-ground fault propagated through $\mathrm{Y}_{0} / \mathrm{Y}-12$ transformer. Amplitude of phase $\mathrm{A}$ is 0.33p.u. , while amplitude of phase $\mathrm{B}$ and $\mathrm{C}$ is 0.88p.u. , in particular $V_{1}=0$. The phase angle jump to phase A is 19.11 degrees. Combining with RMS waveform of figure 4 (b), voltage effective values of phase A, B and C during the fault are $1.49 \mathrm{kV}, 3.35 \mathrm{kV}$ and $3.25 \mathrm{kV}$, respectively. Voltage of phase A is $1.49 / 3.71=0.4$ p.u. , slightly higher than 0.33p.u., and voltage of phase $\mathrm{B}$ and $\mathrm{C}$ are 3.35/3.71 = 0.90p.u. and 3.25/3.71 =0.88p.u., respectively, close to 0.88p.u. .

Phase changes of the transformer secondary are shown in figure 5. The phase difference of AC and $\mathrm{AB}$ during the fault is changed from 120 degrees to 107.7 degrees and 98.24 degrees. Phase shifts are 12.3 degrees and 21.76 degrees to the phase $\mathrm{A}$, respectively.

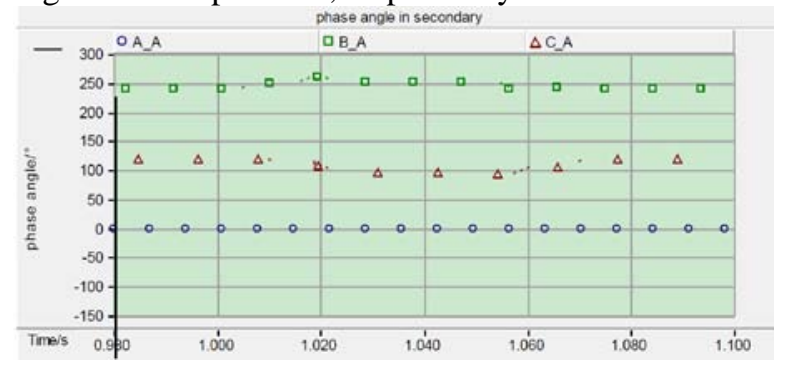

Figure 5. Voltage phase on secondary side of transformer of single phase-to-ground fault 


\subsection{Phase-to-phase fault}

Phase voltage expression of the transformer is shown as (11) when the phase-to-phase fault occurs.

$$
\mathbf{C}_{1}=\left[\begin{array}{l}
\mathbf{U}_{a} \\
\mathbf{U}_{b} \\
\mathbf{U}_{c}
\end{array}\right]=\left[\begin{array}{c}
1 \\
-\frac{1}{2}-j \frac{\sqrt{3}}{2} V_{2} \\
-\frac{1}{2}+j \frac{\sqrt{3}}{2} V_{2}
\end{array}\right]
$$

Where, $V_{2}=\frac{Z_{F 1}}{Z_{S 1}+Z_{F 1}}$

Phase voltage expression in the secondary of the transformer is shown as (12) when the phase-tophase fault propagated by $\mathrm{Y}_{0} / \mathrm{Y}-12$ transformer. Voltage waveforms (RMS) in primary and secondary of the transformer are shown in figure 6 when phase-to-phase fault occurs.

$$
\begin{aligned}
\mathbf{C}_{1}^{\prime \prime} & =\mathbf{T}_{2 P-N} \times \mathbf{C}_{1} \\
& =\frac{1}{3}\left[\begin{array}{ccc}
2 & -1 & -1 \\
-1 & 2 & -1 \\
-1 & -1 & 2
\end{array}\right] \times\left[\begin{array}{c}
1 \\
-\frac{1}{2}-j \frac{\sqrt{3}}{2} V_{2} \\
-\frac{1}{2}+j \frac{\sqrt{3}}{2} V_{2}
\end{array}\right]=\left[\begin{array}{c}
1 \\
-\frac{1}{2}-j \frac{\sqrt{3}}{2} V_{2} \\
-\frac{1}{2}+j \frac{\sqrt{3}}{2} V_{2}
\end{array}\right]
\end{aligned}
$$

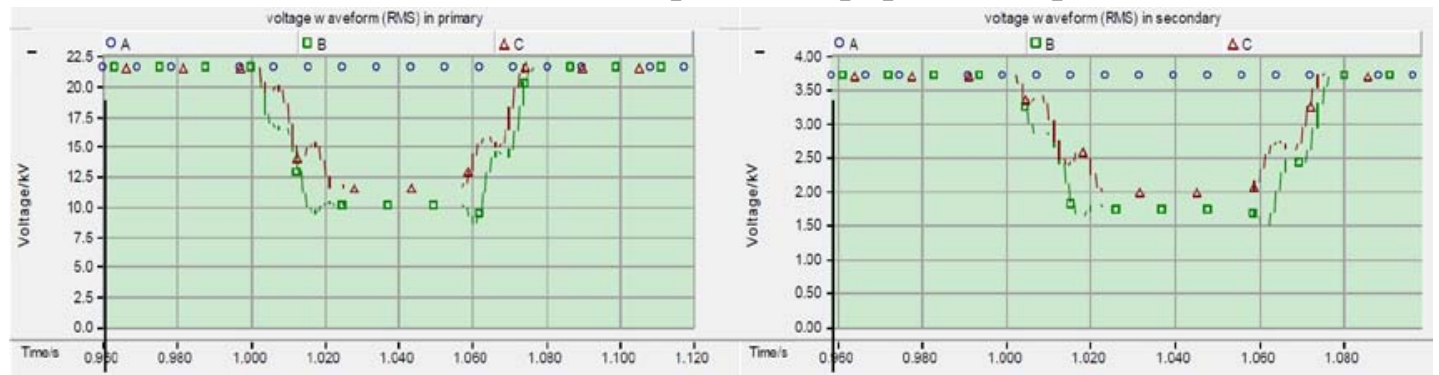

(a)voltage waveform in primary

(b)voltage waveform in secondary

Figure 6. Voltage waveform(RMS) of phase-to-phase fault with $\mathrm{Y}_{0} / \mathrm{Y}-12$ type transformer

Expression (12) indicates that the amplitude of phase A, B and C remained unchanged and the value is 1p.u., $\sqrt{\left(\frac{1}{3} V_{1}+\frac{1}{6}\right)^{2}+\frac{3}{4}}$ p.u. and $\sqrt{\left(\frac{1}{3} V_{1}+\frac{1}{6}\right)^{2}+\frac{3}{4}}$ p.u. , respectively, after voltage sag caused by the single phase-to-ground fault propagated by $\mathrm{Y}_{0} / \mathrm{Y}-12$ transformer. Amplitude of phase A is 1p.u., while amplitude of phase B and $\mathrm{C}$ is 0.5p.u., in particular $V_{2}=0$. Phase angle is opposite to phase A. Combining with RMS waveform of figure 6 (b), voltage effective values of phase A, B and C during the fault are $3.71 \mathrm{kV}, 1.74 \mathrm{kV}$ and $1.99 \mathrm{kV}$, respectively. Voltage of phase A is $3.71 / 3.71=1 \mathrm{p} . u$. and voltage of phase $B$ and $C$ are $1.74 / 3.71=0.47$ p.u. and $1.99 / 3.71=0.54$ p.u., respectively, close to 0.5p.u. .

Phase change of the transformer secondary is shown in figure 7. The phase difference of $A B$ and AC during the fault is187.9 degrees and 173.1 degrees, close to 180 degrees. 


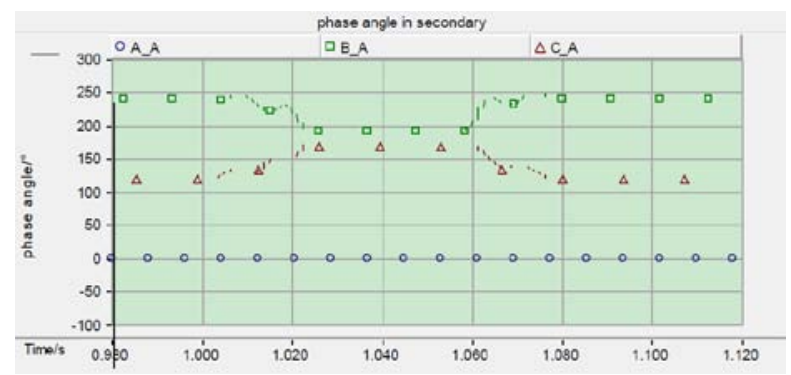

Figure 7. Voltage phase on secondary side of transformer of phase-to-phase fault

\subsection{Two phase-to-ground fault}

Phase voltage expression of the transformer is shown as (13) when the two phase-to-ground fault occurs.

$$
\mathbf{E}_{1}=\left[\begin{array}{l}
\mathbf{U}_{a} \\
\mathbf{U}_{b} \\
\mathbf{U}_{c}
\end{array}\right]=\left[\begin{array}{c}
1 \\
\left(-\frac{1}{2}-j \frac{\sqrt{3}}{2}\right) V_{3} \\
\left(-\frac{1}{2}+j \frac{\sqrt{3}}{2}\right) V_{3}
\end{array}\right]
$$

Where, $V_{3}=\frac{Z_{F 1}}{Z_{S 1}+Z_{F 1}}$

Phase voltage expression in the secondary of the transformer is shown as (14) when the two phaseto-ground fault propagated by $\mathrm{Y}_{0} / \mathrm{Y}-12$ transformer. Voltage waveforms (RMS) in primary and secondary of the transformer are shown in figure 8 when two phase-to-ground fault occurs.

$$
\begin{aligned}
\mathbf{E}_{1}^{\prime \prime}=\mathbf{T}_{2 P-N} \times \mathbf{E}_{1} \\
=\frac{1}{3}\left[\begin{array}{ccc}
2 & -1 & -1 \\
-1 & 2 & -1 \\
-1 & -1 & 2
\end{array}\right] \times\left[\begin{array}{c}
1 \\
\left(-\frac{1}{2}-j \frac{\sqrt{3}}{2}\right) V_{3} \\
\left(-\frac{1}{2}+j \frac{\sqrt{3}}{2}\right) V_{3}
\end{array}\right]=\left[\begin{array}{c}
\frac{2}{3}+\frac{1}{3} V_{3} \\
-\frac{1}{3}-\left(\frac{1}{6}+j \frac{\sqrt{3}}{2}\right) V_{3} \\
-\frac{1}{3}-\left(\frac{1}{6}-j \frac{\sqrt{3}}{2}\right) V_{3}
\end{array}\right]
\end{aligned}
$$

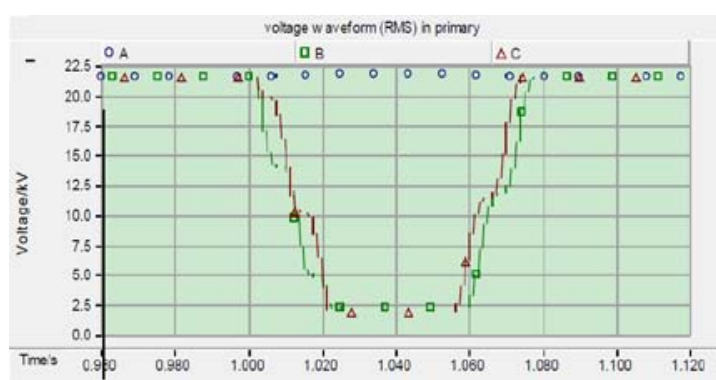

(a)voltage waveform in primary

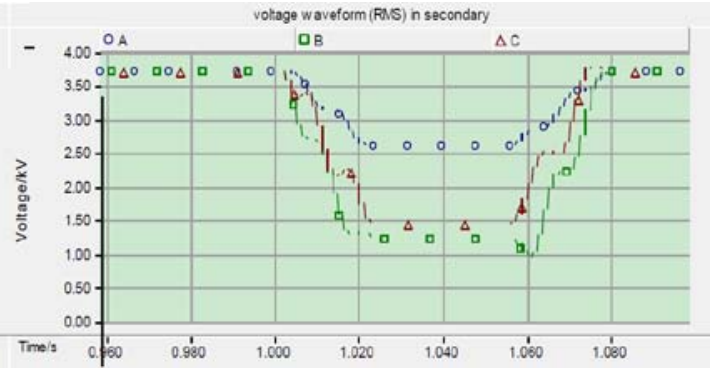

(b)voltage waveform in secondary

Figure 8. Voltage waveform (RMS) of two phase-to-ground fault with $\mathrm{Y}_{0} / \mathrm{Y}-12$ type transformer 
Expression (14) indicates that the amplitude of phase A changed from 1p.u. to $\sqrt{\frac{4}{9}+\frac{1}{9} V_{3}^{2}}$ p.u. , the amplitude of phase $\mathrm{B}$ and $\mathrm{C}$ changed from 0 to $\sqrt{\left(\frac{1}{3}+\frac{1}{6} V_{3}\right)^{2}+\frac{3}{4} V_{3}^{2}}$ p.u. , after voltage sag caused by the two phase-to-ground fault propagated by $\mathrm{Y}_{0} / \mathrm{Y}-12$ transformer. Amplitude of phase $\mathrm{A}$ is 0.66p.u., while amplitude of phase $\mathrm{B}$ and $\mathrm{C}$ is 0.33p.u. , in particular $V_{2}=0$. The change of phase angle is similar to phase-to-phase fault. Combining with RMS waveform of figure 8 (b), voltage effective values of phase A, B and C during the fault are $2.62 \mathrm{kV}, 1.22 \mathrm{kV}$ and $1.45 \mathrm{kV}$, respectively. Voltage of phase A is $2.62 / 3.71=0.71$ p.u. , slightly higher than 0.33p.u.. Voltage of phase $\mathrm{B}$ and $\mathrm{C}$ are $1.22 / 3.71=0.33$ p.u. and $1.45 / 3.71=0.39$ p.u. , respectively, close to 0.33 p.u. .

From above analyses, the amplitude of the phase voltage is not less than 0.33p.u.when three-phase unbalanced sags caused by short circuits propagated through $\mathrm{Y}_{0} / \mathrm{Y}-12$ transformer. So it will not cause the interruption of the voltage in secondary.

The types and the characteristics of voltage sags do not change for $Y_{0} / Y_{0}-12$ transformer because its transformation matrix is unit matrix.

The expression of phase voltage and the propagation matrix indicate that the amplitudes of two phase voltages are not less than 0.58p.u.when three-phase unbalanced sags through $\mathrm{Y}_{0} \Delta-11$ transformer. For single phase-to-ground fault, the other phase voltage is 1p.u.. For phase-to-phase fault and two phase-to-ground fault, the other phase voltage is 0 .

\section{Conclusions}

In this paper, the propagation rules of voltage sags in different connection modes are summarized. The study results show that :

(1)The amplitude of unbalanced voltage sag in secondary is not less than 0.33p.u after the propagation of $\mathrm{Y}_{0} / \mathrm{Y}-12\left(\mathrm{Y} / \mathrm{Y}_{0}-12\right.$ or $\left.\mathrm{Y} / \mathrm{Y}-12\right)$ transformer and will not cause the voltage interruption. Thus, for the single phase load, transformer winding should adopt $\mathrm{Y}_{0} / \mathrm{Y}-12\left(\mathrm{Y} / \mathrm{Y}_{0}-12\right.$ or $\mathrm{Y} / \mathrm{Y}$ 12)connection in upstream.

(2)The amplitudes of two phase voltages in secondary are not less than 0.58p.u. after three-phase unbalanced sags through $\mathrm{Y}_{0} \Delta-11$ or $\mathrm{Y} / \Delta-11$ transformer. So the transformer should be using this connection if the secondary load is factories, enterprises, construction site , mostly.

Therefore, the appropriate transformer winding connection can be selected, according to the load condition of the user side. This could reduce the economic losses caused by the unbalanced voltage sags to the power customers. It is advisable to install DVR (Dynamic Voltage Regulator), UPS (Uninterruptible Power Supply) and other measures to reduce the impact of voltage sags to sensitive equipment. Especialy for voltage sags caused by three-phase short circuit because of the lower remain voltage. In addition, we can also infer the fault type of the bus by the knowing transformer winding connection and fault type of the user side. To provide certain judgment basis for identification of sags types, sags source location and a certain reference for the online monitoring and evaluation of voltage sags.

\section{References}

1. Y. Liu, X.Y. Xiao, Y. Zhang, et al. Interval-Valued Intuitionistic fuzzy assessment on response event of voltage-sag-sensitive process and its risk[J].PST, 39(5) : 1398-1404 (2015).

2. J. Zeng, D. Y. Cai, A Monte Carlo Assessment Method of Voltage Sags Based on Combination Weight[J].PST, 40(5) : 1469-1475 (2016).

3. J.Li, L. Wang, W.B. Chen, Research on Voltage Sag Protection Based on DC Power Supply Technology [J]. JPS, 13(5) : 105-111 (2015). 
4. AQSIQ. GB/T30137-2013 Power quality-voltage dips and short interruptions[S]. CSP, (2013).

5. Q. Tan, Y.H. Xu, H. Huang, et al. A control strategy for peak output current of PV inverter under unbalanced voltage sags[J]. PS T, 39(3):601-608 (2015).

6. C.X. Zhao, S. Tao, X.N. Xiao. An Improved Monitoring Allocation Method by Considering the Propagation of Voltage Sag [J]. MEP, 33(4) : 82-87 (2016).

7. Z.T. He. Research on voltage sag of shenzhen power grid[D]. SCUT, (2014).

8. S. Ouyang, P. Liu, T.T. Wu, et al. Experimental research on sensitivity of low voltage releaser to voltage sag[J]. PST, 39(2) : 575-581 (2015).

9. Z.L. Xiao, R.X. Gong, S. Chen, Detection of voltage sag by a modified incomplete S-transform [J]. PSPC, 43(9) : 62-68 (2015).

10. J.Q. Hu, L.B. Zhang, C.Y. Hu. An early warning method of degradation for mechanical facilities based on data self-organization mining technology[J]. JCUP(ENS), 03 : 142-147 (2014).

11. L.B. Zhang, J.L. Chen, L.X. Duan. Fault diagnosis of reciprocating compressor based on chaos theory[J]. JCUP(ENS), $01:$ 112-116+121 (2012).

12. L. Hung. Research on voltage sag influence the sensitive load and control measures[D]. GDU T, (2012).

13. Y. Tang, J. Chen, X.M. Fan, et al. A Method for Detecting Voltage Sag Sources Based on Disturbance Active Current Direction [J]. TCES, 30(23) : 102-109 (2015).

14. X.Y. Kong, H.Y. Xu, S.Tao. Sensitive Equipment Immunity Assessment Based on a New Voltage Sag Description [J]. TCES, 30(3) : 165-171 (2015).

15. Mustapa R F, Serwan M S, Hamzah N, et al. The propagation of voltage sag through transformer connections in a power system network[C]. PEOCO. IEEE, 1-6 (2010).

16. R. Chen. Research on propagation regularity and simulation assessment of voltage sags in distribution system[D]. NCEPU (BJ), (2007).

17. S. Tao, X.N. Xiao. Voltage Sags Types Under Different Grounding Modes of Neutral and Their Propagation : Part II[J]. TCES, 22(10) : 156-159 (2007).

18. Aung M T, Milanovic J V. The influence of transformer winding connections on the propagation of voltage sags[J]. IEEE TPD, 21(1) : 262-269 (2006). 